\title{
The Access of Romanian Rural Population to the Information and Communication Technology
}

\author{
Cristina Bianca POCOL ${ }^{1 *}$, Ioana Delia POP ${ }^{2)}$ \\ 1) Faculty of Horticulture, University of Agricultural Sciences and Veterinary Medicine of Cluj Napoca, \\ 3-5, Mănăștur Street, Cluj Napoca, Romania. \\ ${ }^{*}$ Corresponding authors, e-mails: cristina.pocol@usamvcluj.ro
}

Bulletin UASVM Horticulture 71(2) / 2014

Print ISSN 1843-5254, Electronic ISSN 1843-5394

DOI:10.15835/buasvmcn-hort:10696

\begin{abstract}
Using information and communication technology in rural areas contributes to human development and to poverty reduction in these areas. The study aims to assess the access to ICT of the rural population in Romania between 2007-2013. The main parameters analyzed were the share of households from rural area to a computer and those with access to Internet at home. The data were provided by the National Institute of Statistics. The results show a progress in the analyzed period, however, insufficient compared with other rural areas from EU countries.
\end{abstract}

Keywords: development, communication, information, rural, technology.

Introduction. Information and Communication Technology plays a major role in rural development (Chapman and Slaymaker, 2002). According to UN's Report on Human Development, no individual, organization, economic entity or government can ignore the importance of new technologies for the development of society (UNDP, 2014). Using ICT means to connect different stakeholders interested in identifying needs and offering solutions, this being even more important in rural areas, exposed to poverty. An advantage of using ICT is low-cost information access (Mathur and Ambani, 2005). One of the main predictors of adopting ICT in rural areas is education, this one having a more powerful influence than income (Tengtrakul and Peha, 2011).

Aims and objectives. Evaluation of population's access to ICT in Romanian rural areas aims to identify the share of households with access to a computer at home, those with access to Internet, the types of connections used and the motivation for accessing the Internet.

Materials and methods. The study is based on the analysis of data provided by INS, through the data basis TEMPO-Online. There was performed a quantitative analysis of relevant parameters, obtained from secondary statistic data, the methodology using Desk Research.

Results and Discussion. The share of households from rural areas with access to a computer at home increased between 2007-2013, from $11.9 \%$ to $37.5 \%$ (fig. 1).

Despite the progress recorded, Romania is still facing significant disparities between rural and urban areas $(37.5 \%$ compared to $55.8 \%$ in 2013). The number of persons between 16-74 years who have ever used the computer increased in the period analysed from 1583160 to 3139775 (fig. 2). In 2013, 53\% of these persons used the computer on a daily basis, $31.2 \%$ at least once a week and $15.8 \%$ at least once a month. According to The Information Society Statistics at regional level (Eurostat, 2014), at least 35\% of the population has never used a computer in 26 EU regions belonging to Italy, Romania, Bulgaria, Greece, Spain and Poland.

A significant evolution in Romania was recorded for the category of households with access to Internet at home: if in 2007, only $3 \%$ of the households were connected to the Internet, in 2013 studies show that it has been reached a share ten times higher, respectively of $32.8 \%$ (fig. 3 ). 


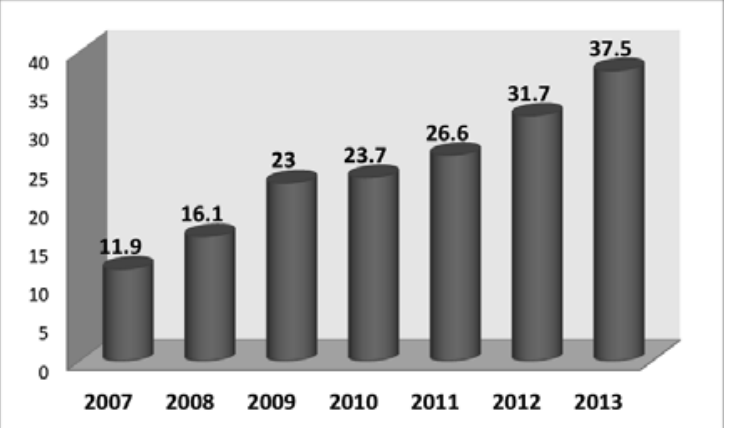

Fig. 1: The evolution of households from rural areas with access to a computer at home, 2007-2013 (\%)

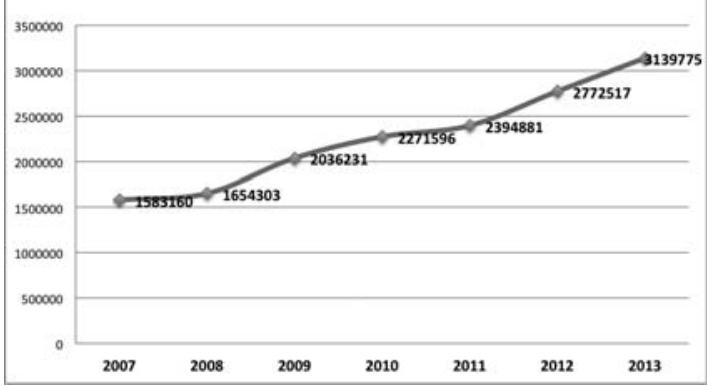

Fig. 2: The number of persons, who have used the computer in rural areas, between 2007-2013 Source: own processing of data provided by the National Institute of Statistics, 2014

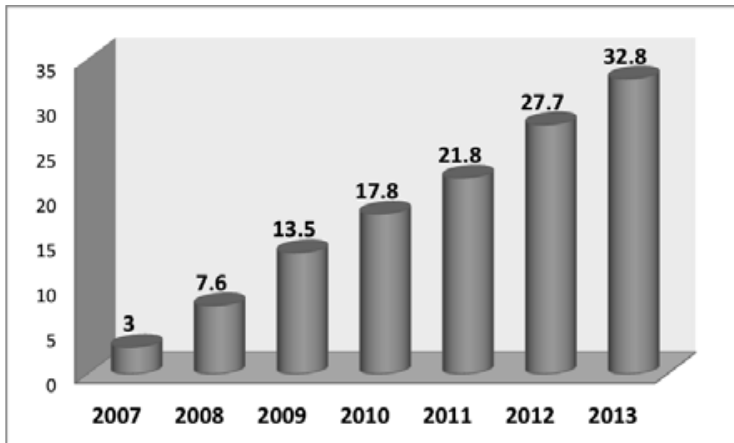

Fig. 3: The evolution of households from rural areas with access to Internet at home, 2007-2013 (\%) Source: own processing of data provided by the National Institute of Statistics, 2014

The main method of accessing the Internet in rural areas, in 2010, was the PC (93.8\%), followed by the laptop (9.1\%). As for the types of connections used, the fixed cable connection is on the first place, followed by modem and ISDN connections. The motivation behind accessing the Internet in 2013 was mainly to communicate and to access diverse information on education, health, goods and services. The connectivity rates at EU 28 level show that $70 \%$ of households in rural areas had a broadband connection in 2013; the biggest gaps between rural and urban were recorded in Romania, Bulgaria, Lithuania and Portugal (Eurostat, 2014).

Conclusion. Using ICT in Romania rural areas recorded progresses between 2007 and 2013, these being insufficient for eliminating disparities compared with other rural areas from EU countries.
Continuing to develop ICT in all Romanian rural areas is a mandatory premise for increasing rural economy and for improving human development.

\section{REFERENCES}

1. Chapman R and Slaymaker T (2002). ICTs and Rural Development: Review of the Literature, Current.

2. Mathur A and Ambani D (2005). ICT and rural societies: Opportunities for growth. The International Information \& Library Review, 37(4), 345-351.

3. Tengtrakul P and Peha JM (2011). Access to and penetration of ICT in rural Thailand. Telecommunications Policy, 35(2), 141-155.

4. ***United Nations Development Programme, 2014, Human Development Report, http://hdr.undp.org/en, accessed on 30th of July 2014.

5. ***Eurostat, 2014, Information society statistics at regional level.

6. ${ }^{* * *}$ National Institute of Statistics, 2014, Tempo - time series, Living Standard, Population access to ITC. 